\title{
Possible Clues for Brain Energy Translation via Endolysosomal Trafficking of APP-CTFs in Alzheimer's Disease
}

\author{
Senthilkumar Sivanesan $\mathbb{D}^{1},{ }^{1}$ Ravi Mundugaru, ${ }^{1}$ and Jayakumar Rajadas $\mathbb{D}^{2,3}$ \\ ${ }^{1}$ Department of Research and Development, Saveetha Institute of Medical and Technical Sciences, Chennai 602 105, India \\ ${ }^{2}$ Biomaterials and Advanced Drug Delivery Laboratory, Stanford University School of Medicine, Stanford, CA 94305, USA \\ ${ }^{3}$ Department of Bioengineering and Therapeutic Sciences, Schools of Pharmacy and Medicine, University of California San Francisco, \\ San Francisco, CA 94158, USA \\ Correspondence should be addressed to Senthilkumar Sivanesan; senbio@gmail.com and Jayakumar Rajadas; jayraja@stanford.edu
} Received 10 April 2018; Revised 14 July 2018; Accepted 19 August 2018; Published 21 October 2018

Academic Editor: Marcelo Mori

Copyright ( 2018 Senthilkumar Sivanesan et al. This is an open access article distributed under the Creative Commons Attribution License, which permits unrestricted use, distribution, and reproduction in any medium, provided the original work is properly cited.

Vascular dysfunctions, hypometabolism, and insulin resistance are high and early risk factors for Alzheimer's disease (AD), a leading neurological disease associated with memory decline and cognitive dysfunctions. Early defects in glucose transporters and glycolysis occur during the course of AD progression. Hypometabolism begins well before the onset of early AD symptoms; this timing implicates the vulnerability of hypometabolic brain regions to beta-secretase 1 (BACE-1) upregulation, oxidative stress, inflammation, synaptic failure, and cell death. Despite the fact that ketone bodies, astrocyte-neuron lactate shuttle, pentose phosphate pathway (PPP), and glycogenolysis compensate to provide energy to the starving $\mathrm{AD}$ brain, a considerable energy crisis still persists and increases during disease progression. Studies that track brain energy metabolism in humans, animal models of $\mathrm{AD}$, and in vitro studies reveal striking upregulation of beta-amyloid precursor protein $(\beta$-APP) and carboxyterminal fragments (CTFs). Currently, the precise role of CTFs is unclear, but evidence supports increased endosomal-lysosomal trafficking of $\beta$-APP and CTFs through autophagy through a vague mechanism. While intracellular accumulation of $\mathrm{A} \beta$ is attributed as both the cause and consequence of a defective endolysosomal-autophagic system, much remains to be explored about the other $\beta$-APP cleavage products. Many recent works report altered amino acid catabolism and expression of several urea cycle enzymes in $\mathrm{AD}$ brains, but the precise cause for this dysregulation is not fully explained. In this paper, we try to connect the role of CTFs in the energy translation process in AD brain based on recent findings.

\section{Introduction}

Alzheimer's disease (AD), a progressive neurodegenerative disorder, evolves over many years and is characterized by episodes of memory impairments, loss of cognitive skills [1], and personality changes [2]. Although both tau and amyloid beta $(\mathrm{A} \beta)$ reportedly play normal functions at the synapse, the transsynaptic spread of pathogenic tau aggregates and accumulation of toxic $\mathrm{A} \beta$ oligomers are together believed to be crucial for synapse loss and neurodegeneration in $\mathrm{AD}$ [3]. Despite marked neuronal death during late $\mathrm{AD}$, it is worthwhile to examine the survival of a limited number of A $\beta$-resistant neurons via increased glucose uptake [4]. Unfortunately, it is difficult to understand how and why only certain nerve cells become resistant to $A \beta$ toxicity, a fact that emphasizes the need to identify precise therapeutic targets for AD. Notably, the toxicity of $\mathrm{A} \beta$ oligomer species occurs within seconds to minutes, although it takes several years to attain disease severity. This inequality, along with disparate results of antiamyloid clinical trials, questions the centrality of $A \beta$ as the chief mediator of neuronal cell death [5]. Moreover, whether $\mathrm{A} \beta$ oligomeric species directly cause $\mathrm{AD}$ is still arguable [6].

Early stages of $\mathrm{AD}$ include white matter changes that involve pericyte degeneration and vascular defects with loss of myelinated axons and oligodendrocytes [7]. Hypometabolism occurs early in $\mathrm{AD}$ progression, with oxidative stress and impaired mitochondrial bioenergetics [8]. Disruption of normal $A \beta$ synaptic signaling and nonfulfillment of synaptic energy demands presumably cause amyloid toxicity and 
metabolic stress [5, 9]. Currently, the amyloid cascade hypothesis accentuates the role of soluble $\mathrm{A} \beta$ oligomers $[10-12]$ and tau aggregates $[13,14]$ in $\mathrm{AD}$ pathogenesis. However, notable emerging views on the role of insulin resistance and hypometabolism connected to $\mathrm{AD}$ suggest that the damage induced by pathogenic $A \beta$ entities could be a secondary effect rather than the early and precise cause of $\mathrm{AD}$.

As part of normal aging, oxygen and glucose metabolic rates are consistently altered in brain cells [15] and are drastically changed in many neurodegenerative diseases [16]. Although numerous alternative pathways could fulfill brain energy needs, there will still be an unmet energy demand [17]. Adenosine triphosphate (ATP) production could be age dependently decreased owing to poor nutrient and oxygen supply as well as reduced rates of glycolysis and oxidative phosphorylation [18]. Brain hypoperfusion and loss of blood-brain barrier (BBB) integrity can diminish nutrient import and/or toxin removal [19]. Recent research focuses on $\mathrm{AD}$ hypometabolism-associated cognitive impairments. Reduced glucose transporter 1 (GLUT1) levels cause an age-dependent decrease in cerebral capillary density, reduced cerebral blood flow and glucose uptake, and increased BBB leakage [20]. Indeed, these metabolic and vascular alterations precede dendritic spine loss in cornu ammonis 1 (CA1) hippocampal neurons, and associated behavioral impairments implicate energy dysfunctions during the course of AD. Several seminal works also implicate alterations in spine shape, density, and size of aged neurons, indicative of gross changes in dendritic structures [18].

The precise cellular events of hypometabolism associated with $\mathrm{AD}$ progression are poorly understood. Unfortunately, apart from ketone bodies, astrocyte-neuron lactate shuttle, the pentose phosphate pathway (PPP), and glycogenolysis, there are no clear-cut data that support other energy compensatory mechanisms to balance the bioenergetic deficits in $\mathrm{AD}$ brain. Several findings substantiate that plasma levels of certain amino acids are significantly altered in mild cognitive impairment $(\mathrm{MCI})$ and $\mathrm{AD}$ patients compared to control individuals [21-23]. The BBB restricts the entry of glutamate and other anionic excitatory amino acids from the circulation [24], although it allows selective transport of certain amino acids to support neuronal functions through transporters $[25,26]$. However, whether transported amino acids could support brain energy functions during starvation/hypometabolism is not clear. A growing body of evidence suggests that starvation/hypometabolism in $\mathrm{AD}$ brain increases endosomal-lysosomal trafficking of $\beta$-amyloid precursor protein $(\beta$-APP) meant for clearance during autophagy. The intricate role of such events and further functions need to be further explored. Moreover, the apparent cause for abnormal $\beta$-APP processing in AD brains is relatively unclear. This review envisages the importance of vascular abnormalities, hypometabolism, insulin resistance, and altered $\beta$-APP processing in AD along with our hypothetical views on possible energy compensatory mechanisms in $\mathrm{AD}$ brain (Figure 1).

1.1. Hypoxia and Hypometabolism Are Early Events in AD. Cerebral amyloid angiopathy- (CAA-) associated microbleeds are one of several causative factors attributed to brain hypometabolism and atrophy in AD [27]. Vascular risk factors, such as adversely affected hippocampus microvasculature length [28], hypoperfusion [29], hypoxia, and hypometabolism, contribute greatly to early $\mathrm{AD}$ progression [30-34]. A stronger correlation seems to exist between brain energy inhibition and $\mathrm{AD}$ severity $[35,36]$. Consistently, agents used to alleviate brain energy dysfunctions are promising for the treatment of cognitive and neurological diseases including $\mathrm{AD}$ [37-40].

While fludeoxyglucose positron emission tomography $\left({ }^{18} \mathrm{~F}\right.$-FDG-PET) helps to detect the cerebral metabolic rate of glucose metabolism (MRglc) in $\mathrm{AD}$ [41], voxel-based morphometry (VBM) of T1-weighted magnetic resonance imaging (MRI) could reveal brain atrophy [42]. Recent ${ }^{18}$ F-FDGPET studies confirm hypometabolism in early sporadic AD [43, 44]. Moreover, region-specific severe hypometabolism in $\mathrm{AD}$ brain regions shows age invariance with greatly reduced frontal cortex glucose metabolism $[45,46]$. There is a strong correlation between glucose hypometabolism and atrophy in the precuneus in early $\mathrm{AD}$ subjects based on ${ }^{18}$ F-FDG-PET studies [47]. In mild AD subjects, there is significantly lower MRglc in the parietal cortex, posterior cingulate, and thalamus [48]. Different research groups report hypometabolism in $\mathrm{AD} /$ probable $\mathrm{AD}$ subjects in the temporal cortex, bilateral middorsolateral frontal region, frontal brain, and parieto-mesial cortex regions based on ${ }^{18} \mathrm{~F}-\mathrm{FDG}-$ PET $[42,49,50]$. Although Stein et al. [51] identified energy fluctuations manifested as poor glucose metabolic rate in the limbic areas of the temporal lobe, a voxel-based study that analyzed $\mathrm{AD}$ brain regions revealed significant atrophy of the hippocampus and amygdala [52]. Metabolic fluctuations of key glycolytic enzymes [53] and oxygen delivery in the circulating erythrocytes could also be risk factors for brain hypometabolism in $\mathrm{AD}$ [54].

The "Warburg effect," well described for cancer cells, appears to apply to neuronal cells [4], notably during the mild phase of $\mathrm{AD}$ where neurons with defective glucose uptake show resistance to $A \beta$ toxicity. Thus, the predementia phase of $\mathrm{AD}$ provides evidence of gray matter loss and brain glucose deficits [55]. Reduced expression of energy metabolism genes that encode subunits of the mitochondrial electron transport chain is also apparent in the posterior cingulate neurons of $\mathrm{AD}$ brains [56]. Mitoenergetic failure develops in $\mathrm{A} \beta$ overexpressing Caenorhabditis elegans, a finding that demonstrates this phenomenon is not unique to human $\mathrm{AD}$ [57]. Using Trem $2^{-/-}$5xFAD transgenic mice, mutations in triggering receptor expressed on myeloid cells 2 (TREM2) can lead to energy dysfunctions in the immune cell microglia and thereby cause impaired clearance of amyloid plaques; energy supplementation with cyclocreatine to immune cells reduces the plaque load to protect the neurons [58]. Altogether, vascular and metabolic fluctuations are well indicated during the early course of $\mathrm{AD}$.

1.2. Defective Glycolytic Enzymes, Glucose Transporters, and Impaired Insulin Signaling in $A D$. It is difficult to determine whether brain hypometabolic status is a consequence or cause of $\mathrm{AD}$ pathology, but many recent works support the 


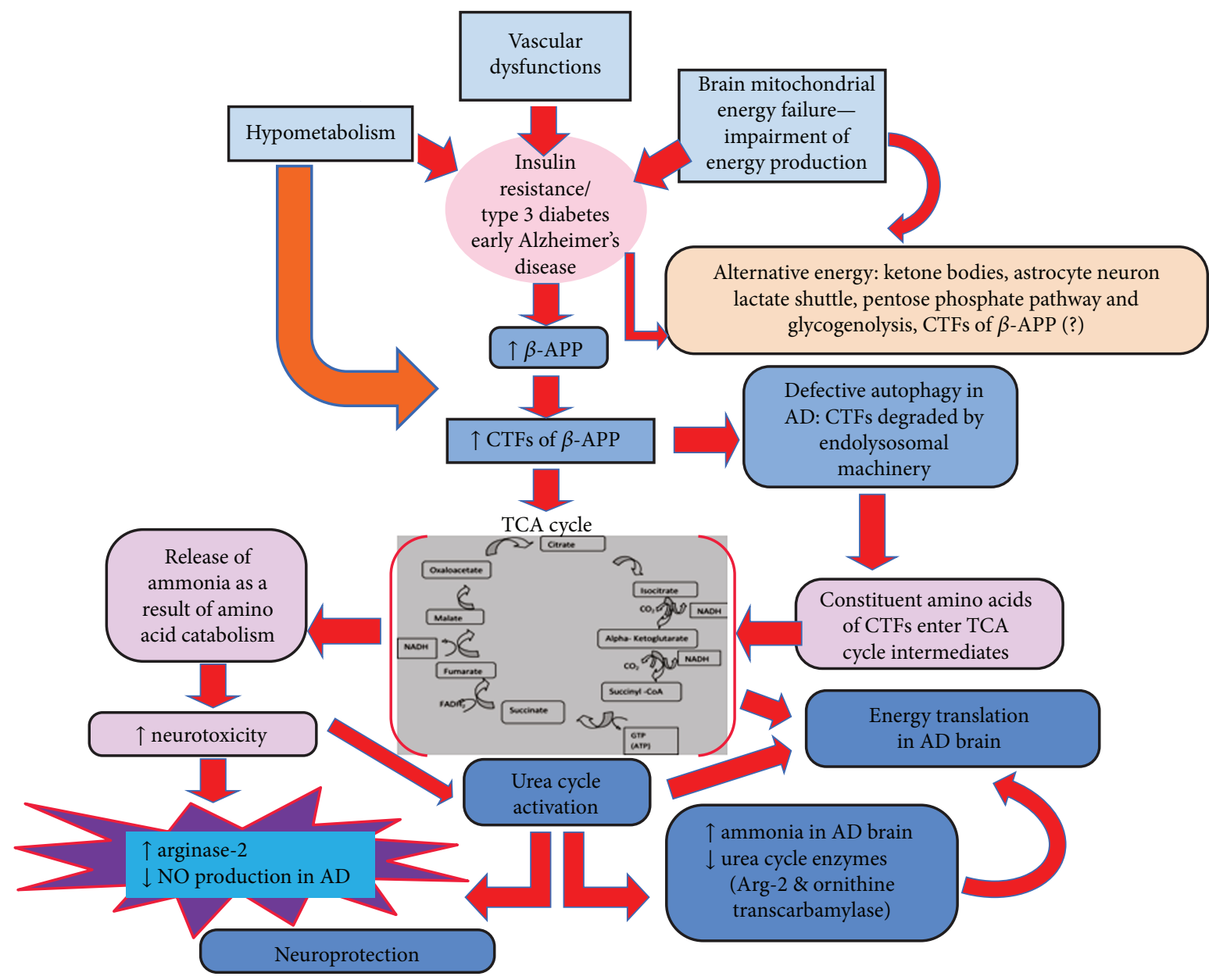

FIGURE 1: Hypothetical scheme that shows the possible energy compensatory mechanism in hypometabolic AD brain through endolysosomal trafficking of CTFs and urea cycle activation.

latter. Elevated plasma glucose concentrations in fasting conditions are attributed to increased brain glucose levels in $\mathrm{AD}$, a finding that implicates insulin resistance [59]. Human and animal studies clearly show reduced expression of glucose transporters in aged [60] and AD [59] brains, including changes in the expression of key enzymes involved in glycolysis and oxidative phosphorylation [61-63]. Evidence supports considerable neuronal loss in $\mathrm{AD}$ brain that involves oxidative stress-mediated inhibition of glyceraldehyde-3-phosphate dehydrogenase (GAPDH) activity [64]. The reduced flux of pyruvate carboxylase (PC) in gluconeogenesis and pentose phosphate from the hexose monophosphate shunt reported in the brains of $\mathrm{A} \beta \mathrm{PP}-\mathrm{PS} 1$ mice (an AD model) further indicates poor glucose metabolism [65]. A study with Thy-1 mito-CFP mice showed reduced ATP levels in white matter during aging, in correlation with ultrastructural alterations in mitochondria, as well as reduced association of mitochondria with the endoplasmic reticulum [66]. The van GijselBonnello et al. group [67] recently performed metabolomic analysis using $5 \mathrm{xFAD}$ transgenic mouse astrocytes and showed marked changes in the glycolytic pathway and tricarboxylic acid cycle (TCA).

A considerable number of research substantiates glucose transporter defects $[20,68-70]$, neurovascular dysfunctions associated with glucose transporter defects [20], poor glucose utilization [71, 72], and cognitive dysfunctions [73] in $\mathrm{AD}$. The defective insulin signaling mechanisms reported in $\mathrm{AD}$ [70, 74-77] further strengthen the vascular and metabolic anomalies in $\mathrm{AD}$, and the disease could be described as type 3 diabetes $[78,79]$. Therefore, therapeutics aimed towards curing $\mathrm{AD}$ would need to significantly rely on regulating insulin levels and brain cellular energy levels [80-84]. Insulin improves cognition and may be neuroprotective, yet different intranasal insulin concentrations exert varying responses in subsets of $\mathrm{AD}$ patients $[39,40,84-86]$.

1.3. Hypoxia and Energy Stress/Starvation Influences $\beta$-APP Processing and Beta-Secretase 1 (BACE1) Levels. Defective glycolysis [59] and oxidative phosphorylation tend to be part of the metabolic adaptation process implicated as early signs of sporadic AD [15]. Substantial evidence pinpoints that hypoxia significantly increases BACE1 gene expression through hypoxia-inducible factor 1-alpha ( $\mathrm{Hif} 1 \alpha)$ upregulation [32, 87-89]. Although increased BACE1 activity reduces mitochondrial glucose uptake [90], a majority of work supports the view that BACE1 upregulation accounts for energy inhibition [36, 91-93]. Gabuzda et al. [94] explored energyrelated metabolic stress on APP processing using sodium 
azide and agents that inhibit protein transport in the secretory pathway (monensin and brefeldin A). These agents could ultimately drive oxidative energy impairment in mitochondria to alter several-fold APP proteolytic processing into an $11.5 \mathrm{kDa}$ carboxy terminal fragment. In another work, Velliquette et al. [91] revealed that energy inhibition by agents such as insulin, 2-deoxyglucose, 3-nitropropionic acid, and kainic acid in wild-type and Tg2576 transgenic mice strikingly elevates cerebral BACE1 levels concomitant with progressive AD pathology. Xiong et al. [93] inhibited mitochondrial complex I, II, and IV with rotenone, nitropropionic acid, and sodium azide, respectively, to prove that mitochondrial respiratory inhibition and oxidative stress trigger BACE1 expression as well as the presence of $\beta$-APP carboxy terminal fragments. Gatta et al. [92] inhibited heme synthesis and mitochondrial energy production using small interfering RNA and N-methylprotoporphyrin IX; these actions alter APP processing and amyloid aggregation. In another work [95], fasting differentially activates macroautophagy in 5xFAD mouse neurons compared to control mice. Fasting alters the numbers and pattern of autophagosomes in neurons, although the study suggests that activated macroautophagy after fasting does not degrade intracellular $\mathrm{A} \beta$ that is increased due to enhanced uptake from the extracellular space [95]. Inhibition of the key glycolytic enzyme 6-phosphofructo-2-kinase in astrocyte cultures increases amyloidogenic processing of APP [96]. Unfortunately, the cause for increased BACE1 and $\beta$-APP processing in conditions such as energy inhibition, starvation, and hypometabolism in $\mathrm{AD}$ brain is still unclear. However, there is a plausible relationship between hypometabolism and autophagy. Specifically, defects in mammalian target of rapamycin (mTOR) signaling in AD brain correlate with impaired mitochondrial functions and energy metabolism [97]. Whether hypometabolism precedes defective autophagy or the vice versa requires further exploration.

1.4. Connection between Early Autophagy/Macrophagy and $\beta-A P P$ Processing. Macroautophagy activation occurs during conditions such as cellular stress due to nutritional deficit or cell injury [98]. This process represents a lysosomal pathway for the turnover of organelles and longlived proteins and is a key determinant of cell survival and longevity [99]. While chaperone-mediated autophagy (CMA) involves chaperone-mediated degradation of proteins near the lysosomal lumen that have specific sequence signals [100], macroautophagy degrades misfolded and aggregated proteins by lysosomal machinery [101]. Using a fusion protein called tandem-fluorescent-APP, investigators showed that starvation triggers the trafficking of APP and APP-carboxy-terminal fragments (APP-CTFs) to the degradative endolysosomal network, a finding that provides a new hint for identifying key therapeutics for AD [102]. A more recent work indicates increased BACE1 turnover in the vicinity of suppressed autophagy after lysosomal inhibition [103]. Since BACE1 recruitment to the autophagy pathway and its comigration with autophagic vacuoles seems to occur similarly along the entire axon, autophagic induction with concomitant BACE1 retention could promote increased
$\beta$-APP cleavage processing. Taken together, the protective role of autophagy elicited under metabolic stress conditions reveals bioenergetic adaptations in the cellular environment [104]. Thus, autophagy could provide compensatory regulation of brain energy through the APP trafficking pathway.

Culminating evidence pinpoints early induction of neuronal macroautophagy in sporadic $\mathrm{AD}$ brains and transgenic mouse models of AD pathology even before the visualization of extracellular $\mathrm{A} \beta$ deposits $[99,105]$. While dystrophic dendrites are the sites where autophagosomes and late autophagic vacuoles (AVs) accumulate, it is possible that purified AVs are the source of APP, beta-cleaved APP, presenilin 1 , nicastrin, and $\gamma$-secretase activity. Nonetheless, Boland et al. [106] reveal that although neuronal macroautophagy does not directly regulate APP metabolism, there is plausible proof for an antiamyloidogenic role of lysosomal proteolysis in postsecretase APP-CTF catabolism. Indeed, agents/drugs that can reduce $\mathrm{A} \beta$ levels in the brain probably account for the increased degradation of APPCTFs as well as $\mathrm{A} \beta$ clearance [107].

1.5. Amino Acid Sensing in Lysosomes Provides Hints about the Brain Energy Translation Process. The role of lysosomal machinery in the degradation and recycling of cellular waste is not novel. Moreover, the localization of lysosomal hydrolases within neurons is a feature of AD [108]. However, compelling evidence supports additional lysosomal machinery functions involved in secretion, plasma membrane repair, and energy metabolism [109]. While several studies provide mechanistic insights about the lysosome and cellular energy metabolism [109-112], much remains to be explored in brain regions and particularly in $\mathrm{AD}$. Other studies show a favoring of amino acid sensing and mTOR signaling promoted by vacuolar $\mathrm{H}^{+}$-ATPase within the lysosomal compartment [113-115]. In a recent review, Carroll and Dunlop [116] detail the role of lysosomes in autophagy, in amino acid sensing by mTOR complex 1 (mTORC1), and the key signaling events associated among lysosomes, adenosine monophosphate-activated protein kinase (AMPK), and mTORC1. Considering this point of view, the events associated with endosomal-lysosomal trafficking of $\beta$-APP $[102,117]$ need much more exploration to support energy-related functions of cleaved APP fragments.

1.6. Culminating Work Shows Amino Acid Catabolism and Urea Cycle Activation in AD Brain. While ketone bodies [118, 119], PPP [67], and astrocyte-neuron lactate shuttle [120] try to compensate for AD brain energy deficits, there is still (to some extent) an increasing demand for brain energy. Urea cycle activation in $\mathrm{AD}$ brain [121-123] to remove ammonia generated from increased amino acid catabolism [121, 123, 124] provides evident and plausible insights into amino acid catabolism for energy conversion. $\mathrm{AD}$ brains exhibit increased expression of carbamoyl phosphate synthetase 1 (CPS-1) and peptidylarginine deiminase (PAD), which catalyzes the conversion of arginine into citrulline during ammonia formation [124]. The normal brain lacks urea-cycle-related ornithine transcarbamylase (OTC) and CPS-1 enzymes, a finding that strengthens the fact that 


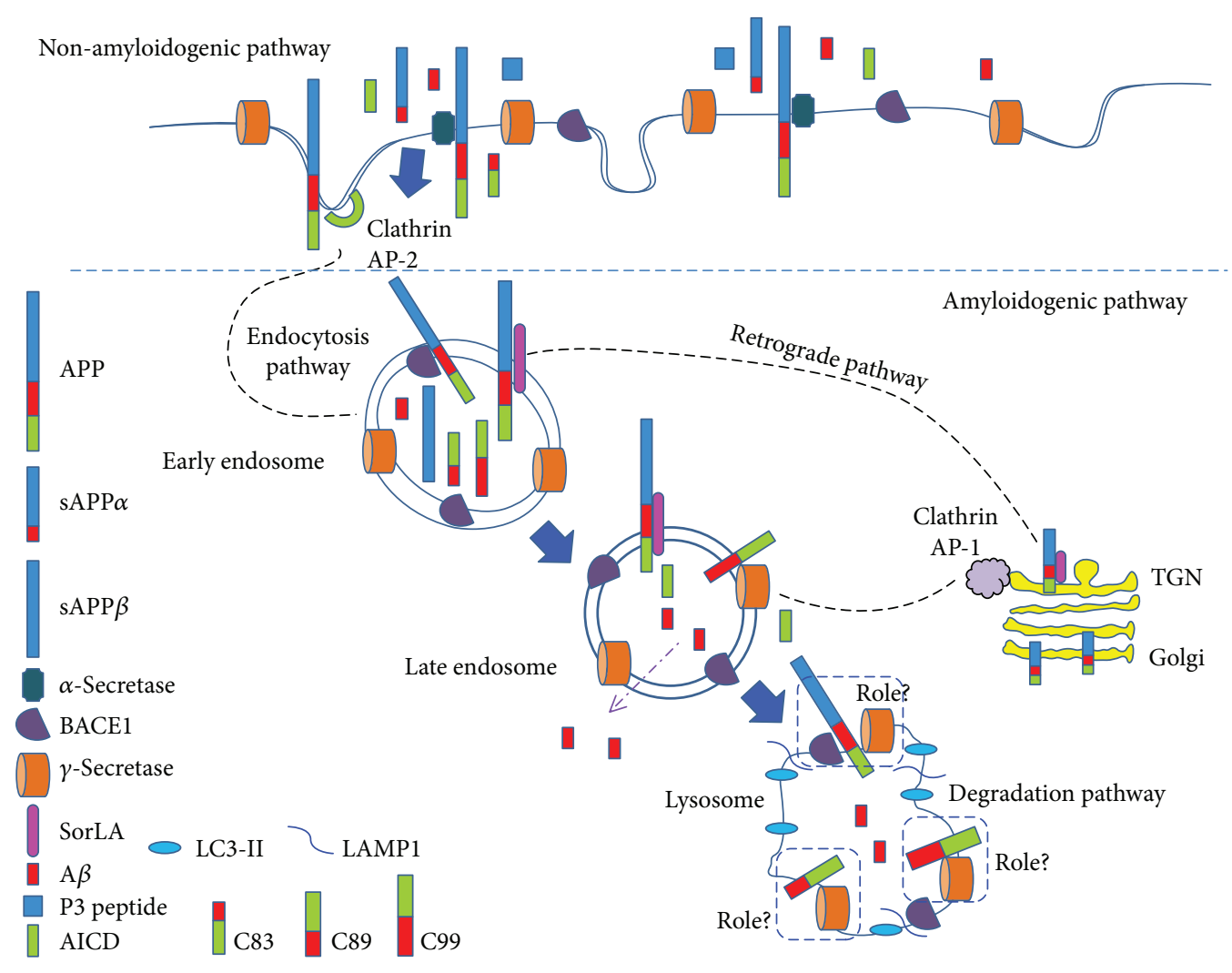

FIGURe 2: Pathways involved in the proteolytic processing of $\beta$-APP in AD.

$\mathrm{AD}$ brains are vulnerable to ammonia toxicity. Favorably, defects in ammonia detoxification owing to the adversely affected energy-producing pathway of glucose metabolism (involving PC and PPP) were reported in 20-month-old A $\beta$ PP-PS1 mice [65].

According to Seiler [125], hyperammonemia in the blood and brain of $\mathrm{AD}$ subjects can provoke toxicity, contribute to $\mathrm{AD}$ pathogenesis, and alter $\beta$-APP processing in the lysosome. Ammonia is the major end product of cellular amino acid metabolism [126], and the brain can derive ammonia from both endogenous and exogenous pathways [125, 127]. Endogenous sources include degradation of neurotransmitters (glutamate, aspartate, and other monoamines), amino acids (e.g., glutamine, asparagine, and glycine), and hexamines. Deamination of amino-purines, amino-pyrimidines, and oxidative deamination of primary amines overall contribute to the endogenous sources of brain ammonia. Given the fact that the urea cycle in $\mathrm{AD}$ brains generates copious amounts of ammonia, a considerable amount of protein degradation must occur during AD pathogenesis. Increasing evidence pinpoints amino acid catabolism $[128,129]$ and ammonia accumulation in $\mathrm{AD}$ brain $[128,130,131]$, although the exact processes remain unclear. However, such notable findings could indicate activation of energy compensation regulatory mechanisms in hypometabolic $\mathrm{AD}$ brain. Findings from Hansmannel et al. [121] strikingly reveal that all urea cycle enzymes are expressed in $\mathrm{AD}$ brain, with notably increased arginase-2 (Arg2) gene expression compared to control. Moreover, vulnerable AD brain regions exhibit region-specific alterations in arginase and nitric oxide synthase (NOS) [132]. OTC induction and Arg2 upregulation in $\mathrm{AD}$ would attempt to reduce brain ammonia, including reduction of $\mathrm{NO}$ and inducible NOS levels, actions that may emphasize the intricate neuroprotective role of the urea cycle pathway [121]. In Huntington's disease (HD), another neurodegenerative disease, markedly elevated toxic urea levels in the brain before dementia onset precede brain damage in a transgenic sheep HD model and human subjects [133]. Since urea and ammonia are the key metabolic units of protein catabolism, there is a clear-cut indication for major protein catabolism in neurodegenerative $\mathrm{HD}$ and $\mathrm{AD}$. Interestingly, a recent ongoing phase 2 clinical trials for $\mathrm{AD}$ is testing AMX0035 which is an oral formulation of two drugs, sodium phenylbutyrate $(\mathrm{PB})$ and tauroursodeoxycholic-acid (TUDCA). While PB is an FDA-approved drug prescribed for urea-cycle disorders to reduce toxic unfolded proteins, TUDCA helps in reducing cellular energy loss.

1.7. Evidence Spotlights the Importance of APP-CTFs-Derived Amino Acids in Brain Energy Functions in AD. Serum and cerebrospinal fluid metabolomics studies reveal major alterations in canonical energy metabolism pathways, Krebs cycle, mitochondrial function and amino acid metabolism in $\mathrm{MCI}$ and $\mathrm{AD}$ patients [22]. Since starvation promotes trafficking of both APP and APP-CTFs to the degradative endolysosome [102], it provides clues for compensatory mechanisms initiated to counterbalance the energy deficits. Proteolytic processing of APP mainly involves amyloidogenic and nonamyloidogenic pathways $[134,135]$ as detailed below (Figure 2). BACE1 cleavage of APP within its 
extracellular/luminal domain represents the amyloidogenic pathway and promotes shedding of soluble $\beta$-secreted APP $(\operatorname{sAPP} \beta)$ and membrane-associated C-terminal fragment of 99 amino acids $(\beta \mathrm{CTF} / \mathrm{C} 99)$ or 89 amino acids $(\beta \mathrm{CTF} /$ C89). After ectodomain shedding, $\gamma$-secretase (protein complex comprised of presenilin 1 or 2, Aph1 homolog A or B, nicastrin, and presenilin enhancer protein 2) cleavage occurs in the membrane-tethered C89 and C99 and thereby releasing $\mathrm{p} 3$ from $\mathrm{C} 89$ or $\mathrm{A} \beta$ peptides from $\mathrm{C} 99$. The nonamyloidogenic pathway at the plasma membrane involves cleavage by $\alpha$-secretases (ADAM10/ADAM17) that generates soluble $\alpha$-secreted $\operatorname{APP}(\operatorname{sAPP} \alpha)$ and a C-terminal membrane-bound fragment of 83 amino acids ( $\alpha$ CTF/C83). Further cleavage of this fragment by $\gamma$-secretase releases the p3 peptide. The retrograde trafficking mechanisms that follow either $\alpha$ - or $\beta$-secretase cleavage allow delivery of APPCTFs to the trans-Golgi network (TGN). Based on recent findings, the majority of $\gamma$-secretase cleavage of APP occurs in the TGN [136]. Notably, $\gamma$-secretase cleavage of both $\beta \mathrm{CTF} / \mathrm{C} 99$ and $\alpha \mathrm{CTF} / \mathrm{C} 83$ generates the APP intracellular domain (AICD), but it is rapidly degraded similar to p3. Growing evidence depicts novel/alternative metabolic processing pathways ( $\eta$-secretase, $\delta$-secretase, and meprin pathways) during physiological processing of APP [137, 138]. Usually, carboxy-terminal fragments, such as $\beta \mathrm{CTF} / \mathrm{C} 89$, $\beta \mathrm{CTF} / \mathrm{C} 99$, and $\alpha \mathrm{CTF} / \mathrm{C} 83$, are targeted to the endosomallysosomal compartment $[102,139]$. The biological importance of $\beta \mathrm{CTF} / \mathrm{C} 99, \beta \mathrm{CTF} / \mathrm{C} 89, \alpha \mathrm{CTF} / \mathrm{C} 83$, and $\mathrm{p} 3$ remains unclear [135], although many studies substantiate the neuroprotective functions of $\operatorname{sAPP} \alpha$, including in brain development, growth factor, neural cell proliferation [140, 141], and synaptic plasticity [142]. sAPP $\beta$ is involved in pruning of synapses during the development of both central and peripheral neurons [143] but reported to cause suppression of neuronal stem cell differentiation [144]. Although controversies exist about the biological functions of the AICD fragment, it is reported to be involved in gene transcription, cytoskeletal dynamics, and apoptosis [145]. However, during lysosomal degradation that recruits various CTFs $(\beta \mathrm{CTF} /$ $\mathrm{C} 89, \beta \mathrm{CTF} / \mathrm{C} 99$, and $\alpha \mathrm{CTF} / \mathrm{C} 83)$, it is likely that constitutive amino acids formed after proteolytic cleavage could serve as TCA cycle intermediates to fulfill brain energy deficits [146]. It remains elusive whether cleaved amino acids from APP after degradation in endolysosomes [102] also provide energy via the TCA cycle. This could be due to the fact that during APP sorting, beclin1 promotes targeting of a smaller fraction of surface-internalized APP to microtubule-associated protein 1 light chain 3- (LC3-) positive phagophores for degradation [147]. According to Hoyer et al. [148], hypoxia/sodium azide insults in HEK293 cells stably transfected with bAPP695 show energy failure with strikingly elevated ATP turnover and adenosine levels that parallel intracellular APP increases. In another work, upon hypoglycemic induction, rat neuronal cultures increase utilization of amino acids as evidenced by ammonia formation due to amino acid catabolism [149]. Overall, there is a considerable body of evidence that supports $\beta$-APP energyrelated functions during $\mathrm{AD}$ hypometabolism. Further detailed investigations are warranted on APP-related energy functions in order to accurately track the pathological cascade to develop precise therapeutic targets. Recently, a study revealed that a greater number of dendritic spines in healthy brains (controls) compared to age-matched AD brains poorly correlate with symptoms such as dementia in controls, despite marked amyloid plaques and tangles observed in both types of brains [150]. This intriguing result demarcates the disease and healthy brains from the amyloid cascade hypothesis and creates avenues for further exploration in $\mathrm{AD}$ research.

\section{Summary}

$\mathrm{AD}$ brain is vulnerable to increased $\beta$-APP proteolytic cleavage and accumulation of various CTFs as well as APP in the endolysosomal compartment. While these intricate events are complicated, the relative cause and functions of cleavage products are poorly understood. In this paper, we hypothesize that in hypometabolic AD brains, the constitutive amino acids of CTFs and APP formed during endolysosomal degradation could compensate for metabolic demands through the TCA cycle. Our hypothetical views on APP-related brain energy functions can be justified with numerous recent works that implicate amino acid catabolism, urea cycle activation (due to increased amino acid catabolism), and ammonia toxicity propagated in AD brain. We also try to connect possible neuroprotective mechanisms in $\mathrm{AD}$ brain against ammonia toxicity through activation of urea cycle enzymes (Arg-2 and OTC) and decreased nitric oxide (NO) levels.

\section{Conflicts of Interest}

The authors declare no competing financial interests.

\section{Acknowledgments}

The authors sincerely thank Dr. Mathew D. Howell for providing critical English and grammar corrections in the manuscript.

\section{References}

[1] R. Tarawneh and D. M. Holtzman, "The clinical problem of symptomatic Alzheimer disease and mild cognitive impairment," Cold Spring Harbor Perspectives in Medicine, vol. 2, no. 5, pp. 1-16, 2012.

[2] F. C. Bozzola, P. B. Gorelick, and S. Freels, "Personality changes in Alzheimer's disease," Archives of Neurology, vol. 49, no. 3, pp. 297-300, 1992.

[3] T. L. Spires-Jones and B. T. Hyman, "The intersection of amyloid beta and tau at synapses in Alzheimer's disease," Neuron, vol. 82, no. 4, pp. 756-771, 2014.

[4] A. Atlante, L. de Bari, A. Bobba, and G. Amadoro, "A disease with a sweet tooth: exploring the Warburg effect in Alzheimer's disease," Biogerontology, vol. 18, no. 3, pp. 301319, 2017.

[5] P. A. Engel, "Does metabolic failure at the synapse cause Alzheimer's disease?," Medical Hypotheses, vol. 83, no. 6, pp. 802-808, 2014. 
[6] G. P. Morris, I. A. Clark, and B. Vissel, "Inconsistencies and controversies surrounding the amyloid hypothesis of Alzheimer's disease," Acta Neuropathologica Communications, vol. 2, no. 1, p. 135, 2014.

[7] A. Montagne, A. M. Nikolakopoulou, Z. Zhao et al., "Pericyte degeneration causes white matter dysfunction in the mouse central nervous system," Nature Medicine, vol. 24, no. 3, pp. 326-337, 2018.

[8] J. Yao and R. Diaz Brinton, "Targeting mitochondrial bioenergetics for Alzheimer's prevention and treatment," Current Pharmaceutical Design, vol. 17, no. 31, pp. 34743479, 2011.

[9] J. Godyn, J. Jonczyk, D. Panek, and B. Malawska, "Therapeutic strategies for Alzheimer's disease in clinical trials," Pharmacological Reports, vol. 68, no. 1, pp. 127-138, 2016.

[10] G. M. Shankar, S. Li, T. H. Mehta et al., "Amyloid- $\beta$ protein dimers isolated directly from Alzheimer's brains impair synaptic plasticity and memory," Nature Medicine, vol. 14, no. 8, pp. 837-842, 2008.

[11] D. J. Selkoe and J. Hardy, "The amyloid hypothesis of Alzheimer's disease at 25 years," EMBO Molecular Medicine, vol. 8, no. 6, pp. 595-608, 2016.

[12] S. Sivanesan, A. Tan, and J. Rajadas, "Pathogenesis of Abeta oligomers in synaptic failure," Current Alzheimer Research, vol. 10, no. 3, pp. 316-323, 2013.

[13] G. S. Bloom, "Amyloid- $\beta$ and tau: the trigger and bullet in Alzheimer disease pathogenesis," JAMA Neurology, vol. 71, no. 4, pp. 505-508, 2014.

[14] D. J. Koss, G. Jones, A. Cranston, H. Gardner, N. M. Kanaan, and B. Platt, "Soluble pre-fibrillar tau and $\beta$-amyloid species emerge in early human Alzheimer's disease and track disease progression and cognitive decline," Acta Neuropathologica, vol. 132, no. 6, pp. 875-895, 2016.

[15] M. Mamelak, "Sporadic Alzheimer's disease: the starving brain," Journal of Alzheimer's Disease, vol. 31, no. 3, pp. 459-474, 2012.

[16] S. Hoyer, "The young-adult and normally aged brain. Its blood flow and oxidative metabolism. A review-part I," Archives of Gerontology and Geriatrics, vol. 1, no. 2, pp. 101-116, 1982.

[17] S. Hoyer, "Abnormalities of glucose metabolism in Alzheimer's disease," Annals of the New York Academy of Sciences, vol. 640, no. 1, pp. 53-58, 1991.

[18] S. Camandola and M. P. Mattson, "Brain metabolism in health, aging, and neurodegeneration," The EMBO Journal, vol. 36, no. 11, pp. 1474-1492, 2017.

[19] B. V. Zlokovic, "Neurovascular pathways to neurodegeneration in Alzheimer's disease and other disorders," Nature Reviews. Neuroscience, vol. 12, no. 12, pp. 723-738, 2011.

[20] E. A. Winkler, Y. Nishida, A. P. Sagare et al., "GLUT1 reductions exacerbate Alzheimer's disease vasculo-neuronal dysfunction and degeneration," Nature Neuroscience, vol. 18, no. 4, pp. 521-530, 2015.

[21] G. Ravaglia, P. Forti, F. Maioli et al., "Incidence and etiology of dementia in a large elderly Italian population," Neurology, vol. 64, no. 9, pp. 1525-1530, 2005.

[22] E. Trushina, T. Dutta, X. M. T. Persson, M. M. Mielke, and R. C. Petersen, "Identification of altered metabolic pathways in plasma and CSF in mild cognitive impairment and Alzheimer's disease using metabolomics," PLoS One, vol. 8, no. 5, article e63644, 2013.
[23] G. Corso, A. Cristofano, N. Sapere et al., "Serum amino acid profiles in normal subjects and in patients with or at risk of Alzheimer dementia," Dementia and Geriatric Cognitive Disorders Extra, vol. 7, no. 1, pp. 143-159, 2017.

[24] Q. R. Smith, "Transport of glutamate and other amino acids at the blood-brain barrier," The Journal of Nutrition, vol. 130, no. 4, pp. 1016S-1022S, 2000.

[25] W. M. Pardridge, "Brain metabolism: a perspective from the blood-brain barrier," Physiological Reviews, vol. 63, no. 4, pp. 1481-1535, 1983.

[26] M. S. Malandro and M. S. Kilberg, "Molecular biology of mammalian amino acid transporters," Annual Review of Biochemistry, vol. 65, no. 1, pp. 305-336, 1996.

[27] M. Samuraki, I. Matsunari, M. Yoshita et al., "Cerebral amyloid angiopathy-related microbleeds correlate with glucose metabolism and brain volume in Alzheimer's disease," Journal of Alzheimer's Disease, vol. 48, no. 2, pp. 517-528, 2015.

[28] Y. Decker, A. Müller, E. Németh et al., "Analysis of the vasculature by immunohistochemistry in paraffin-embedded brains," Brain Structure \& Function, vol. 223, no. 2, pp. 1001-1015, 2018.

[29] S. Verclytte, R. Lopes, P. Lenfant et al., "Cerebral hypoperfusion and hypometabolism detected by arterial spin labeling MRI and FDG-PET in early-onset Alzheimer's disease," Journal of Neuroimaging, vol. 26, no. 2, pp. 207-212, 2016.

[30] B. S. Ashok, T. A. Ajith, and S. Sivanesan, "Hypoxia-inducible factors as neuroprotective agent in Alzheimer's disease," Clinical and Experimental Pharmacology \& Physiology, vol. 44, no. 3, pp. 327-334, 2017.

[31] B. Snyder, B. Shell, J. T. Cunningham, and R. L. Cunningham, "Chronic intermittent hypoxia induces oxidative stress and inflammation in brain regions associated with early-stage neurodegeneration," Physiological Reports, vol. 5, no. 9, article e13258, 2017.

[32] A. Salminen, A. Kauppinen, and K. Kaarniranta, "Hypoxia/ ischemia activate processing of amyloid precursor protein: impact of vascular dysfunction in the pathogenesis of Alzheimer's disease," Journal of Neurochemistry, vol. 140, no. 4, pp. 536-549, 2017.

[33] S. Joubert, N. Gour, E. Guedj et al., "Early-onset and lateonset Alzheimer's disease are associated with distinct patterns of memory impairment," Cortex, vol. 74, pp. 217-232, 2016.

[34] P. Grammas, D. Tripathy, A. Sanchez, X. Yin, and J. Luo, "Brain microvasculature and hypoxia-related proteins in Alzheimer's disease," International Journal of Clinical and Experimental Pathology, vol. 4, no. 6, pp. 616-627, 2011.

[35] C. Arias, T. Montiel, R. Quiroz-Báez, and L. Massieu, “ $\beta$ amyloid neurotoxicity is exacerbated during glycolysis inhibition and mitochondrial impairment in the rat hippocampus in vivo and in isolated nerve terminals: implications for Alzheimer's disease," Experimental Neurology, vol. 176, no. 1, pp. 163-174, 2002.

[36] T. O'Connor, K. R. Sadleir, E. Maus et al., "Phosphorylation of the translation initiation factor eIF $2 \alpha$ increases BACE1 levels and promotes amyloidogenesis," Neuron, vol. 60, no. 6, pp. 988-1009, 2008 .

[37] M. H. Rosenbloom, T. R. Barclay, M. Pyle et al., "A singledose pilot trial of intranasal rapid-acting insulin in apolipoprotein E4 carriers with mild-moderate Alzheimer's disease," CNS Drugs, vol. 28, no. 12, pp. 1185-1189, 2014. 
[38] J. Freiherr, M. Hallschmid, W. H. Frey et al., "Intranasal insulin as a treatment for Alzheimer's disease: a review of basic research and clinical evidence," CNS Drugs, vol. 27, no. 7, pp. 505-514, 2013.

[39] C. Benedict, W. H. Frey II, H. B. Schiöth, B. Schultes, J. Born, and M. Hallschmid, "Intranasal insulin as a therapeutic option in the treatment of cognitive impairments," Experimental Gerontology, vol. 46, no. 2-3, pp. 112-115, 2011.

[40] L. R. Hanson and W. H. Frey, "Intranasal delivery bypasses the blood-brain barrier to target therapeutic agents to the central nervous system and treat neurodegenerative disease," BMC Neuroscience, vol. 9, Supplement 3, p. S5, 2008.

[41] Y. Li, J. O. Rinne, L. Mosconi et al., "Regional analysis of FDG and PIB-PET images in normal aging, mild cognitive impairment, and Alzheimer's disease," European Journal of Nuclear Medicine and Molecular Imaging, vol. 35, no. 12, pp. 21692181, 2008

[42] S. Frisch, J. Dukart, B. Vogt et al., "Dissociating memory networks in early Alzheimer's disease and frontotemporal lobar degeneration - a combined study of hypometabolism and atrophy," PLoS One, vol. 8, no. 2, article e55251, 2013.

[43] J. R. Gatchel, N. J. Donovan, J. J. Locascio et al., "Regional $18 \mathrm{~F}$-fluorodeoxyglucose hypometabolism is associated with higher apathy scores over time in early Alzheimer disease," The American Journal of Geriatric Psychiatry, vol. 25, no. 7, pp. 683-693, 2017.

[44] M. Vanhoutte, F. Semah, A. Rollin Sillaire et al., " ${ }^{18}$ F-FDG PET hypometabolism patterns reflect clinical heterogeneity in sporadic forms of early-onset Alzheimer's disease," Neurobiology of Aging, vol. 59, pp. 184-196, 2017.

[45] H. Oh, C. Madison, S. Baker, G. Rabinovici, and W. Jagust, "Dynamic relationships between age, amyloid- $\beta$ deposition, and glucose metabolism link to the regional vulnerability to Alzheimer's disease," Brain, vol. 139, no. 8, pp. 2275-2289, 2016.

[46] Z. Chen and C. Zhong, "Decoding Alzheimer's disease from perturbed cerebral glucose metabolism: implications for diagnostic and therapeutic strategies," Progress in Neurobiology, vol. 108, pp. 21-43, 2013.

[47] S. M. Adriaanse, K. R. A. van Dijk, R. Ossenkoppele et al., "The effect of amyloid pathology and glucose metabolism on cortical volume loss over time in Alzheimer's disease," European Journal of Nuclear Medicine and Molecular Imaging, vol. 41, no. 6, pp. 1190-1198, 2014.

[48] C. A. Castellano, S. Nugent, N. Paquet et al., "Lower brain ${ }^{18} \mathrm{~F}$-fluorodeoxyglucose uptake but normal ${ }^{11} \mathrm{C}$-acetoacetate metabolism in mild Alzheimer's disease dementia," Journal of Alzheimer's Disease, vol. 43, no. 4, pp. 13431353, 2015.

[49] S. M. Adriaanse, A. M. Wink, B. M. Tijms et al., "The association of glucose metabolism and eigenvector centrality in Alzheimer's disease," Brain Connectivity, vol. 6, no. 1, pp. 1-8, 2016.

[50] B. K. P. Woo, D. G. Harwood, R. J. Melrose et al., "Executive deficits and regional brain metabolism in Alzheimer's disease," International Journal of Geriatric Psychiatry, vol. 25, no. 11, pp. 1150-1158, 2010.

[51] D. J. Stein, M. S. Buchsbaum, P. R. Hof, B. V. Siegel Jr, and L. Shihabuddin, "Greater metabolic rate decreases in hippocampal formation and proisocortex than in neocortex in Alzheimer's disease," Neuropsychobiology, vol. 37, no. 1, pp. 10-19, 1998.

[52] G. B. Frisoni, M. Lorenzi, A. Caroli, N. Kemppainen, K. Någren, and J. O. Rinne, "In vivo mapping of amyloid toxicity in Alzheimer disease," Neurology, vol. 72 , no. 17, pp. 1504-1511, 2009.

[53] Y. G. Kaminsky, V. P. Reddy, G. M. Ashraf et al., “Age-related defects in erythrocyte 2,3-diphosphoglycerate metabolism in dementia," Aging and Disease, vol. 4, no. 5, pp. 244-255, 2013.

[54] E. A. Kosenko, L. A. Tikhonova, C. Montoliu, G. E. Barreto, G. Aliev, and Y. G. Kaminsky, "Metabolic abnormalities of erythrocytes as a risk factor for Alzheimer's disease," Frontiers in Neuroscience, vol. 11, p. 728, 2018.

[55] M. A. Araque Caballero, M. Brendel, A. Delker et al., "Mapping 3-year changes in gray matter and metabolism in A $\beta$-positive nondemented subjects," Neurobiology of Aging, vol. 36, no. 11, pp. 2913-2924, 2015.

[56] W. S. Liang, E. M. Reiman, J. Valla et al., “Alzheimer's disease is associated with reduced expression of energy metabolism genes in posterior cingulate neurons," Proceedings of the National Academy of Sciences of the United States of America, vol. 105, no. 11, pp. 4441-4446, 2008.

[57] S. Fong, E. Teo, L. F. Ng et al., "Energy crisis precedes global metabolic failure in a novel Caenorhabditis elegans Alzheimer disease model," Scientific Reports, vol. 6, no. 1, article 33781, 2016.

[58] T. K. Ulland, W. M. Song, S. C. C. Huang et al., "TREM2 maintains microglial metabolic fitness in Alzheimer's disease," Cell, vol. 170, no. 4, pp. 649-663.e13, 2017.

[59] Y. An, V. R. Varma, S. Varma et al., "Evidence for brain glucose dysregulation in Alzheimer's disease," Alzheimer's \& Dementia, vol. 14, no. 3, pp. 318-329, 2018.

[60] F. Ding, J. Yao, J. R. Rettberg, S. Chen, and R. D. Brinton, "Early decline in glucose transport and metabolism precedes shift to ketogenic system in female aging and Alzheimer's mouse brain: implication for bioenergetic intervention," PLoS One, vol. 8, no. 11, article e79977, 2013.

[61] W. Meier-Ruge, P. Iwangoff, K. Reichlmeier, and P. Sandoz, "Neurochemical findings in the aging brain," Advances in Biochemical Psychopharmacology, vol. 23, pp. 323-338, 1980.

[62] G. Ulfert, U. Schmidt, and S. Hoyer, "Glucose and energy metabolism of rat cerebral cortex during aging," Experimental Brain Research, vol. 5, pp. 102-111, 1982.

[63] A. C. Bowling, E. M. Mutisya, L. C. Walker, D. L. Price, L. C. Cork, and M. H. Beal, "Age-dependent impairment of mitochondrial function in primate brain," Journal of Neurochemistry, vol. 60, no. 5, pp. 1964-1967, 1993.

[64] D. A. Butterfield, S. S. Hardas, and M. L. B. Lange, "Oxidatively modified glyceraldehyde-3-phosphate dehydrogenase (GAPDH) and Alzheimer's disease: many pathways to neurodegeneration," Journal of Alzheimer's Disease, vol. 20, no. 2, pp. 369-393, 2010.

[65] V. Tiwari and A. B. Patel, "Pyruvate carboxylase and pentose phosphate fluxes are reduced in A $\beta$ PP-PS1 mouse model of Alzheimer's disease: a ${ }^{13} \mathrm{C}$ NMR study," Journal of Alzheimer's Disease, vol. 41, no. 2, pp. 387-399, 2014.

[66] K. E. Stahon, C. Bastian, S. Griffith, G. J. Kidd, S. Brunet, and S. Baltan, "Age-related changes in axonal and mitochondrial ultrastructure and function in white matter," The Journal of Neuroscience, vol. 36, no. 39, pp. 9990-10001, 2016. 
[67] M. van Gijsel-Bonnello, K. Baranger, P. Benech et al., "Metabolic changes and inflammation in cultured astrocytes from the $5 \mathrm{xFAD}$ mouse model of Alzheimer's disease: alleviation by pantethine," PLoS One, vol. 12, no. 4, article e0175369, 2017.

[68] C. R. Hooijmans, C. Graven, P. J. Dederen, H. Tanila, T. van Groen, and A. J. Kiliaan, "Amyloid beta deposition is related to decreased glucose transporter-1 levels and hippocampal atrophy in brains of aged APP/PS1 mice," Brain Research, vol. 1181, pp. 93-103, 2007.

[69] Y. Liu, F. Liu, K. Iqbal, I. Grundke-Iqbal, and C. X. Gong, "Decreased glucose transporters correlate to abnormal hyperphosphorylation of tau in Alzheimer disease," FEBS Letters, vol. 582, no. 2, pp. 359-364, 2008.

[70] Y. Deng, B. Li, Y. Liu, K. Iqbal, I. Grundke-Iqbal, and C. X. Gong, "Dysregulation of insulin signaling, glucose transporters, $\mathrm{O}$-GlcNAcylation, and phosphorylation of tau and neurofilaments in the brain: Implication for Alzheimer's disease," The American Journal of Pathology, vol. 175, no. 5, pp. 2089-2098, 2009.

[71] I. A. Simpson, K. R. Chundu, T. Davies-Hill, W. G. Honer, and P. Davies, "Decreased concentrations of GLUT1 and GLUT3 glucose transporters in the brains of patients with Alzheimer's disease," Annals of Neurology, vol. 35, no. 5, pp. 546-551, 1994.

[72] S. D. Harr, N. A. Simonian, and B. T. Hyman, "Functional alterations in Alzheimer's disease: decreased glucose transporter 3 immunoreactivity in the perforant pathway terminal zone," Journal of Neuropathology and Experimental Neurology, vol. 54, no. 1, pp. 38-41, 1995.

[73] S. M. Landau, D. Harvey, C. M. Madison et al., "Comparing predictors of conversion and decline in mild cognitive impairment," Neurology, vol. 75, no. 3, pp. 230-238, 2010.

[74] G. S. Watson and S. Craft, "The role of insulin resistance in the pathogenesis of Alzheimer's disease: implications for treatment," CNS Drugs, vol. 17, no. 1, pp. 27-45, 2003.

[75] W. Q. Zhao, F. G. de Felice, S. Fernandez et al., "Amyloid beta oligomers induce impairment of neuronal insulin receptors," The FASEB Journal, vol. 22, no. 1, pp. 246-260, 2008.

[76] L. M. Chua, M. L. Lim, P. R. Chong, Z. P. Hu, N. S. Cheung, and B. S. Wong, "Impaired neuronal insulin signaling precedes $\mathrm{A} \beta 42$ accumulation in female $\mathrm{A} \beta \mathrm{PPsw} / \mathrm{PS} 1 \Delta \mathrm{E} 9$ mice," Journal of Alzheimer's Disease, vol. 29, no. 4, pp. 783-791, 2012.

[77] S. T. Ferreira, J. R. Clarke, T. R. Bomfim, and F. G. De Felice, "Inflammation, defective insulin signaling, and neuronal dysfunction in Alzheimer's disease," Alzheimers Dement, vol. 10, no. 1, pp. S76-S83, 2014.

[78] S. M. De la Monte and J. R. Wands, "Alzheimer's disease is type 3 diabetes-evidence reviewed," Journal of Diabetes Science and Technology, vol. 2, no. 6, pp. 1101-1113, 2008.

[79] H. Pilcher, "Alzheimer's disease could be "type 3 diabetes", " Lancet Neurology, vol. 5, no. 5, pp. 388-389, 2006.

[80] C. G. Jolivalt, C. A. Lee, K. K. Beiswenger et al., "Defective insulin signaling pathway and increased glycogen synthase kinase-3 activity in the brain of diabetic mice: parallels with Alzheimer's disease and correction by insulin," Journal of Neuroscience Research, vol. 86, no. 15, pp. 3265-3274, 2008.

[81] H. B. Schioth, S. Craft, S. J. Brooks, W. H. Frey, and C. Benedict, "Brain insulin signaling and Alzheimer's disease: current evidence and future directions," Molecular Neurobiology, vol. 46, no. 1, pp. 4-10, 2012.

[82] T. R. Bomfim, L. Forny-Germano, L. B. Sathler et al., “An anti-diabetes agent protects the mouse brain from defective insulin signaling caused by Alzheimer's disease- associated A $\beta$ oligomers," The Journal of Clinical Investigation, vol. 122, no. 4, pp. 1339-1353, 2012.

[83] F. G. De Felice, "Alzheimer's disease and insulin resistance: translating basic science into clinical applications," The Journal of Clinical Investigation, vol. 123, no. 2, pp. 531-539, 2013.

[84] S. M. De la Monte, "Intranasal insulin therapy for cognitive impairment and neurodegeneration: current state of the art," Expert Opinion on Drug Delivery, vol. 10, no. 12, pp. 1699-1709, 2013.

[85] M. A. Reger, G. S. Watson, P. S. Green et al., "Intranasal insulin administration dose-dependently modulates verbal memory and plasma amyloid- $\beta$ in memory-impaired older adults," Journal of Alzheimer's Disease, vol. 13, no. 3, pp. 323-331, 2008.

[86] S. Craft, L. D. Baker, T. J. Montine et al., "Intranasal insulin therapy for Alzheimer disease and amnestic mild cognitive impairment: a pilot clinical trial," Archives of Neurology, vol. 69, no. 1, pp. 29-38, 2012.

[87] X. Sun, G. He, H. Qing et al., "Hypoxia facilitates Alzheimer's disease pathogenesis by up-regulating $B A C E 1$ gene expression," Proceedings of the National Academy of Sciences of the United States of America, vol. 103, no. 49, pp. 1872718732, 2006.

[88] X. Zhang, K. Zhou, R. Wang et al., "Hypoxia-inducible factor $1 \alpha(\mathrm{HIF}-1 \alpha)$-mediated hypoxia increases BACE1 expression and $\beta$-amyloid generation," The Journal of Biological Chemistry, vol. 282, no. 15, pp. 10873-10880, 2007.

[89] M. Guglielmotto, M. Aragno, R. Autelli et al., "The upregulation of BACE1 mediated by hypoxia and ischemic injury: role of oxidative stress and HIF1 $\alpha$," Journal of Neurochemistry, vol. 108, no. 4, pp. 1045-1056, 2009.

[90] J. A. Findlay, D. L. Hamilton, and M. L. J. Ashford, "BACE1 activity impairs neuronal glucose oxidation: rescue by betahydroxybutyrate and lipoic acid," Frontiers in Cellular Neuroscience, vol. 9, article 382, 2015.

[91] R. A. Velliquette, T. O'Connor, and R. Vassar, "Energy inhibition elevates $\beta$-secretase levels and activity and is potentially amyloidogenic in APP transgenic mice: possible early events in Alzheimer's disease pathogenesis," The Journal of Neuroscience, vol. 25, no. 47, pp. 10874-10883, 2005.

[92] L. B. Gatta, M. Vitali, R. Verardi, P. Arosio, and D. Finazzi, "Inhibition of heme synthesis alters amyloid precursor protein processing," Journal of Neural Transmission, vol. 116, no. 1, pp. 79-88, 2009.

[93] K. Xiong, H. Cai, X. G. Luo, R. G. Struble, R. W. Clough, and $\mathrm{X}$. X. Yan, "Mitochondrial respiratory inhibition and oxidative stress elevate $\beta$-secretase (BACE1) proteins and activity in vivo in the rat retina," Experimental Brain Research, vol. 181, no. 3, pp. 435-446, 2007.

[94] D. Gabuzda, J. Busciglio, L. B. Chen, P. Matsudaira, and B. A. Yankner, "Inhibition of energy metabolism alters the processing of amyloid precursor protein and induces a potentially amyloidogenic derivative," The Journal of Biological Chemistry, vol. 269, no. 18, pp. 13623-13628, 1994.

[95] X. Chen, K. Kondo, K. Motoki, H. Homma, and H. Okazawa, "Fasting activates macroautophagy in neurons of Alzheimer's 
disease mouse model but is insufficient to degrade amyloidbeta," Scientific Reports, vol. 5, no. 1, article 12115, 2015.

[96] W. Fu, D. Shi, D. Westaway, and J. H. Jhamandas, "Bioenergetic mechanisms in astrocytes may contribute to amyloid plaque deposition and toxicity," The Journal of Biological Chemistry, vol. 290, no. 20, pp. 12504-12513, 2015.

[97] M. Perluigi, F. Di Domenico, and D. A. Butterfield, "mTOR signaling in aging and neurodegeneration: at the crossroad between metabolism dysfunction and impairment of autophagy," Neurobiology of Disease, vol. 84, pp. 39-49, 2015.

[98] D. C. Rubinsztein, M. DiFiglia, N. Heintz et al., “Autophagy and its possible roles in nervous system diseases, damage and repair," Autophagy, vol. 1, no. 1, pp. 11-22, 2005.

[99] W. H. Yu, A. M. Cuervo, A. Kumar et al., "Macroautophagya novel $\beta$-amyloid peptide-generating pathway activated in Alzheimer's disease," The Journal of Cell Biology, vol. 171, no. 1, pp. 87-98, 2005.

[100] A. M. Cuervo and J. F. Dice, "A receptor for the selective uptake and degradation of proteins by lysosomes," Science, vol. 273, no. 5274, pp. 501-503, 1996.

[101] B. Loos, D. J. Klionsky, and E. Wong, "Augmenting brain metabolism to increase macro- and chaperone-mediated autophagy for decreasing neuronal proteotoxicity and aging," Progress in Neurobiology, vol. 156, pp. 90-106, 2017.

[102] L. K. Hein, P. M. Apaja, K. Hattersley et al., "A novel fluorescent probe reveals starvation controls the commitment of amyloid precursor protein to the lysosome," Biochimica et Biophysica Acta (BBA) - Molecular Cell Research, vol. 1864, no. 10, pp. 1554-1565, 2017.

[103] T. Feng, P. Tammineni, C. Agrawal, Y. Y. Jeong, and Q. Cai, "Autophagy-mediated regulation of BACE1 protein trafficking and degradation," Biological Chemistry, vol. 292, no. 5, pp. 1679-1690, 2017.

[104] S. Giordano, M. Dodson, S. Ravi et al., "Bioenergetic adaptation in response to autophagy regulators during rotenone exposure," Journal of Neurochemistry, vol. 131, no. 5, pp. 625-633, 2014.

[105] L. Holcomb, M. N. Gordon, E. McGowan et al., “Accelerated Alzheimer-type phenotype in transgenic mice carrying both mutant amyloid precursor protein and presenilin 1 transgenes," Nature Medicine, vol. 4, no. 1, pp. 97-100, 1998.

[106] B. Boland, D. A. Smith, D. Mooney, S. S. Jung, D. M. Walsh, and F. M. Platt, "Macroautophagy is not directly involved in the metabolism of amyloid precursor protein," The Journal of Biological Chemistry, vol. 285, no. 48, pp. 37415-37426, 2010.

[107] M. Shinohara, N. Sato, H. Kurinami et al., "Reduction of brain $\beta$-amyloid (A $\beta$ ) by fluvastatin, a hydroxymethylglutaryl-CoA reductase inhibitor, through increase in degradation of amyloid precursor protein C-terminal fragments (APP-CTFs) and $\mathrm{A} \beta$ clearance," The Journal of Biological Chemistry, vol. 285, no. 29, pp. 22091-22102, 2010.

[108] R. A. Nixon, J. Wegiel, A. Kumar et al., "Extensive involvement of autophagy in Alzheimer disease: an immunoelectron microscopy study," Journal of Neuropathology and Experimental Neurology, vol. 64, no. 2, pp. 113-122, 2005.

[109] C. Settembre, A. Fraldi, D. L. Medina, and A. Ballabio, "Signals from the lysosome: a control centre for cellular clearance and energy metabolism," Nature Reviews. Molecular Cell Biology, vol. 14, no. 5, pp. 283-296, 2013.
[110] C. Y. Lim and R. Zoncu, "The lysosome as a command-andcontrol center for cellular metabolism," The Journal of Cell Biology, vol. 214, no. 6, pp. 653-664, 2016.

[111] V. K. Mony, S. Benjamin, and E. J. O'Rourke, "A lysosomecentered view of nutrient homeostasis," Autophagy, vol. 12, no. 4, pp. 619-631, 2016.

[112] C. Settembre, R. Zoncu, D. L. Medina et al., "A lysosometo-nucleus signalling mechanism senses and regulates the lysosome via mTOR and TFEB," The EMBO Journal, vol. 31, no. 5, pp. 1095-1108, 2012.

[113] R. Zoncu, L. Bar-Peled, A. Efeyan, S. Wang, Y. Sancak, and D. M. Sabatini, "mTORC1 senses lysosomal amino acids through an inside-out mechanism that requires the vacuolar $\mathrm{H}^{+}$-ATPase," Science, vol. 334, no. 6056, pp. 678-683, 2011.

[114] J. L. Jewell, R. C. Russell, and K. L. Guan, "Amino acid signalling upstream of mTOR," Nature Reviews. Molecular Cell Biology, vol. 14, no. 3, pp. 133-139, 2013.

[115] D. C. I. Goberdhan, C. Wilson, and A. L. Harris, "Amino acid sensing by mTORC1: intracellular transporters mark the spot," Cell Metabolism, vol. 23, no. 4, pp. 580-589, 2016.

[116] B. Carroll and E. A. Dunlop, "The lysosome: a crucial hub for AMPK and mTORC1 signalling," The Biochemical Journal, vol. 474, no. 9, pp. 1453-1466, 2017.

[117] J. H. K. Tam, M. R. Cobb, C. Seah, and S. H. Pasternak, "Tyrosine binding protein sites regulate the intracellular trafficking and processing of amyloid precursor protein through a novel lysosome-directed pathway," PLoS One, vol. 11, no. 10, article e0161445, 2016.

[118] S. C. Cunnane, A. Courchesne-Loyer, V. St-Pierre et al., "Can ketones compensate for deteriorating brain glucose uptake during aging? Implications for the risk and treatment of Alzheimer's disease," Annals of the New York Academy of Sciences, vol. 1367, no. 1, pp. 12-20, 2016.

[119] K. Heininger, “A unifying hypothesis of Alzheimer's disease. IV. Causation and sequence of events," Reviews in the Neurosciences, vol. 11, pp. 213-328, 2000.

[120] L. Pellerin and P. J. Magistretti, "Sweet sixteen for ANLS," Journal of Cerebral Blood Flow and Metabolism, vol. 32, no. 7, pp. 1152-1166, 2012.

[121] F. Hansmannel, A. Sillaire, M. I. Kamboh et al., "Is the urea cycle involved in Alzheimer's disease?," Journal of Alzheimer's Disease, vol. 21, no. 3, pp. 1013-1021, 2010.

[122] F. Bensemain, D. Hot, S. Ferreira et al., "Evidence for induction of the ornithine transcarbamylase expression in Alzheimer's disease," Molecular Psychiatry, vol. 14, no. 1, pp. 106-116, 2009.

[123] J. Xu, P. Begley, S. J. Church et al., "Graded perturbations of metabolism in multiple regions of human brain in Alzheimer's disease: snapshot of a pervasive metabolic disorder," Biochimica et Biophysica Acta (BBA) - Molecular Basis of Disease, vol. 1862, no. 6, pp. 1084-1092, 2016.

[124] J. Cicolini, Y. Jing, H. J. Waldvogel, R. L. M. Faull, and P. Liu, "Urea cycle enzymes and peptidylarginine deiminase in Alzheimer's superior frontal gyrus," Alzheimer's \& Dementia, vol. 12, no. 7, p. P460, 2016.

[125] N. Seiler, “Ammonia and Alzheimer's disease," Neurochemistry International, vol. 41, no. 2-3, pp. 189-207, 2002.

[126] P. A. Wright, "Nitrogen excretion: three end products, many physiological roles," Journal of Experimental Biology, vol. 198, Part 2, pp. 273-281, 1995. 
[127] M. J. O'Donnell, "Mechanisms of excretion and ion transport in invertebrates," in Comparative Physiology, W. H. Dantzler, Ed., pp. 1207-1289, Oxford University Press, New York, NY, USA, 1997.

[128] J. W. D. Griffin and P. C. Bradshaw, "Amino acid catabolism in Alzheimer's disease brain: friend or foe?," Oxidative Medicine and Cellular Longevity, vol. 2017, Article ID 5472792, 15 pages, 2017.

[129] H. Gallart-Ayala, T. Teav, F. Mehl et al., "Altered brain metabolism in Alzheimer disease: linking peripheral and central metabolic changes," in MSACL 2017 EU Abstract, Salzburg, Austria, September 2017.

[130] A. J. Cooper and T. M. Jeitner, "Central role of glutamate metabolism in the maintenance of nitrogen homeostasis in normal and hyperammonemic brain," Biomolecules, vol. 6, no. 2, 2016.

[131] A. Adlimoghaddam, M. G. Sabbir, and B. C. Albensi, "Ammonia as a potential neurotoxic factor in Alzheimer's disease," Frontiers in Molecular Neuroscience, vol. 9, p. 57, 2016.

[132] P. Liu, M. S. Fleete, Y. Jing et al., "Altered arginine metabolism in Alzheimer's disease brains," Neurobiology of Aging, vol. 35, no. 9, pp. 1992-2003, 2014.

[133] R. R. Handley, S. J. Reid, R. Brauning et al., "Brain urea increase is an early Huntington's disease pathogenic event observed in a prodromal transgenic sheep model and HD cases," Proceedings of the National Academy of Sciences of the United States of America, vol. 114, no. 52, pp. E11293E11302, 2017.

[134] B. De Strooper and W. Annaert, "Proteolytic processing and cell biological functions of the amyloid precursor protein," Journal of Cell Science, vol. 113, Part 11, pp. 1857-1870, 2000.

[135] V. W. Chow, M. P. Mattson, P. C. Wong, and M. Gleichmann, "An overview of APP processing enzymes and products," Neuromolecular Medicine, vol. 12, no. 1, pp. 1-12, 2010.

[136] R. W.-Y. Choy, Z. Cheng, and R. Schekman, "Amyloid precursor protein (APP) traffics from the cell surface via endosomes for amyloid $\beta(\mathrm{A} \beta)$ production in the transGolgi network," Proceedings of the National Academy of Sciences of the United States of America, vol. 109, no. 30, pp. E2077-E2082, 2012.

[137] R. Coronel, A. Bernabeu-Zornoza, C. Palmer et al., "Role of amyloid precursor protein (APP) and its derivatives in the biology and cell fate specification of neural stem cells," Molecular Neurobiology, vol. 55, no. 9, pp. 7107-7117, 2018.

[138] E. Norstrom, "Metabolic processing of the amyloid precursor protein - new pieces of the Alzheimer's puzzle," Discovery Medicine, vol. 23, no. 127, pp. 269-276, 2017.

[139] Q. Xiao, P. Yan, X. Ma et al., "Neuronal-targeted TFEB accelerates lysosomal degradation of APP, reducing $\mathrm{A} \beta$ generation and amyloid plaque pathogenesis," The Journal of Neuroscience, vol. 35, no. 35, pp. 12137-12151, 2015.

[140] M. Gralle, M. G. Botelho, and F. S. Wouters, "Neuroprotective secreted amyloid precursor protein acts by disrupting amyloid precursor protein dimers," The Journal of Biological Chemistry, vol. 284, no. 22, pp. 15016-15025, 2009.

[141] M. P. Demars, C. Hollands, K. D. (. T.). Zhao, and O. Lazarov, "Soluble amyloid precursor protein- $\alpha$ rescues age-linked decline in neural progenitor cell proliferation," Neurobiology of Aging, vol. 34, no. 10, pp. 2431-2440, 2013.
[142] S. H. Tyan, A. Y. J. Shih, J. J. Walsh et al., "Amyloid precursor protein (APP) regulates synaptic structure and function," Molecular and Cellular Neurosciences, vol. 51, no. 1-2, pp. 43-52, 2012.

[143] A. Nikolaev, T. McLaughlin, D. D. M. O’Leary, and M. Tessier-Lavigne, "APP binds DR6 to trigger axon pruning and neuron death via distinct caspases," Nature, vol. 457, no. 7232, pp. 981-989, 2009.

[144] Y. D. Kwak, C. L. Brannen, T. Qu et al., "Amyloid precursor protein regulates differentiation of human neural stem cells," Stem Cells and Development, vol. 15, no. 3, pp. 381-389, 2006.

[145] T. Müller, H. E. Meyer, R. Egensperger, and K. Marcus, “The amyloid precursor protein intracellular domain (AICD) as modulator of gene expression, apoptosis, and cytoskeletal dynamics-relevance for Alzheimer's disease," Progress in Neurobiology, vol. 85, no. 4, pp. 393-406, 2008.

[146] S. Senthilkumar and R. Jayakumar, "Can proteolytic events of $\beta$-APP pave pathway for brain energy metabolism in human Alzheimer models?," Journal of Neurological Sciences [Turkish], vol. 21, pp. 147-154, 2004.

[147] G. Swaminathan, W. Zhu, and E. D. Plowey, "BECN1/Beclin 1 sorts cell-surface APP/amyloid $\beta$ precursor protein for lysosomal degradation," Autophagy, vol. 12, no. 12, pp. 24042419, 2016.

[148] A. Hoyer, H. J. Bardenheuer, E. Martin, and K. Plaschke, "Amyloid precursor protein (APP) and its derivatives change after cellular energy depletion. An in vitro-study," Journal of Neural Transmission, vol. 112, no. 2, pp. 239-253, 2005.

[149] P. Honegger, O. Braissant, H. Henry et al., "Alteration of amino acid metabolism in neuronal aggregate cultures exposed to hypoglycaemic conditions," Journal of Neurochemistry, vol. 81, no. 6, pp. 1141-1151, 2002.

[150] B. D. Boros, K. M. Greathouse, E. G. Gentry et al., "Dendritic spines provide cognitive resilience against Alzheimer's disease," Annals of Neurology, vol. 82, no. 4, pp. 602-614, 2017. 


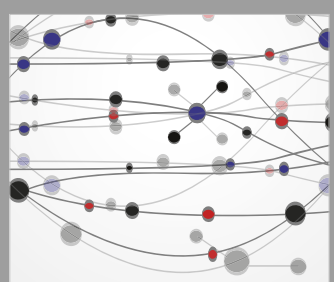

The Scientific World Journal
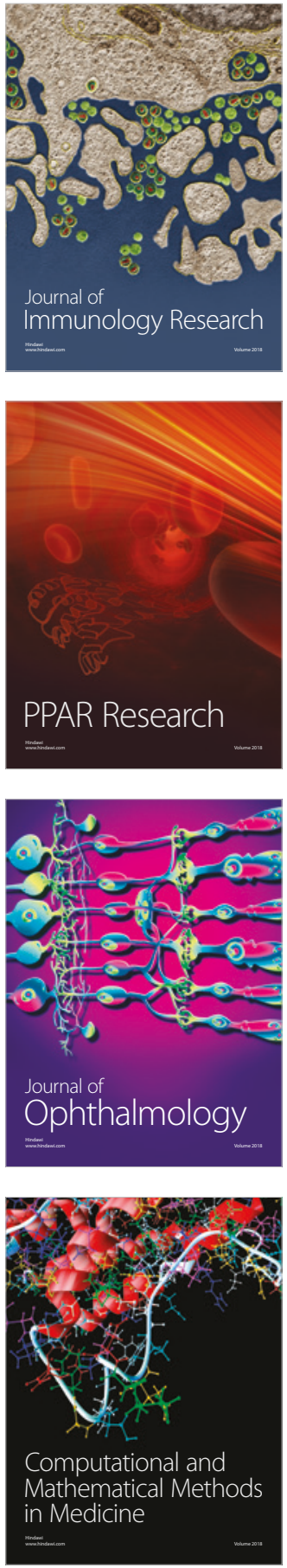

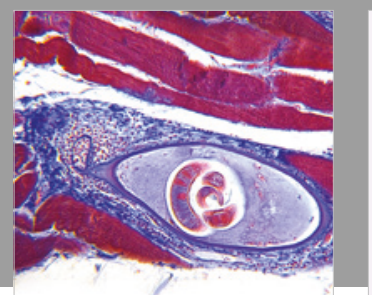

Gastroenterology Research and Practice

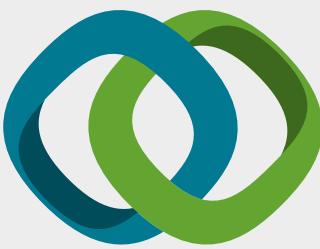

\section{Hindawi}

Submit your manuscripts at

www.hindawi.com
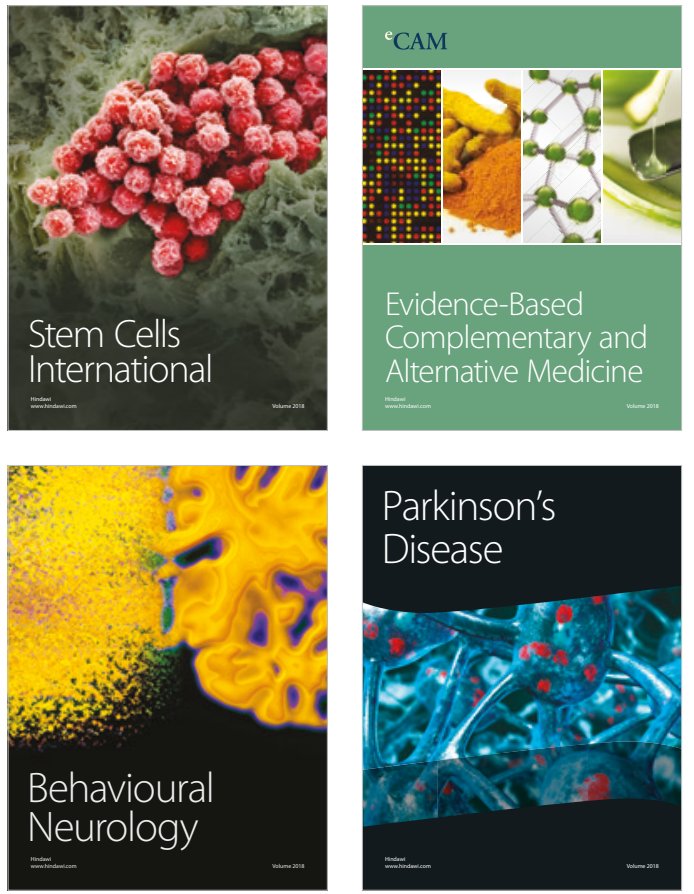

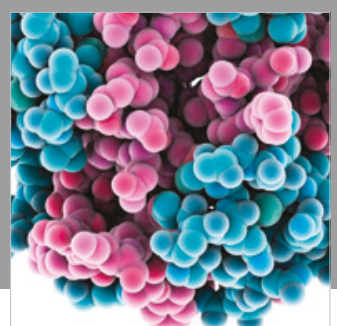

ournal of

Diabetes Research

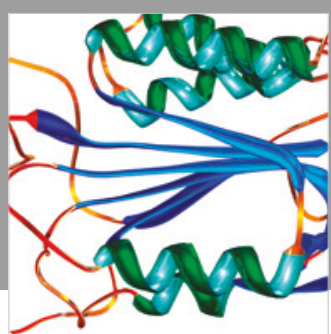

Disease Markers
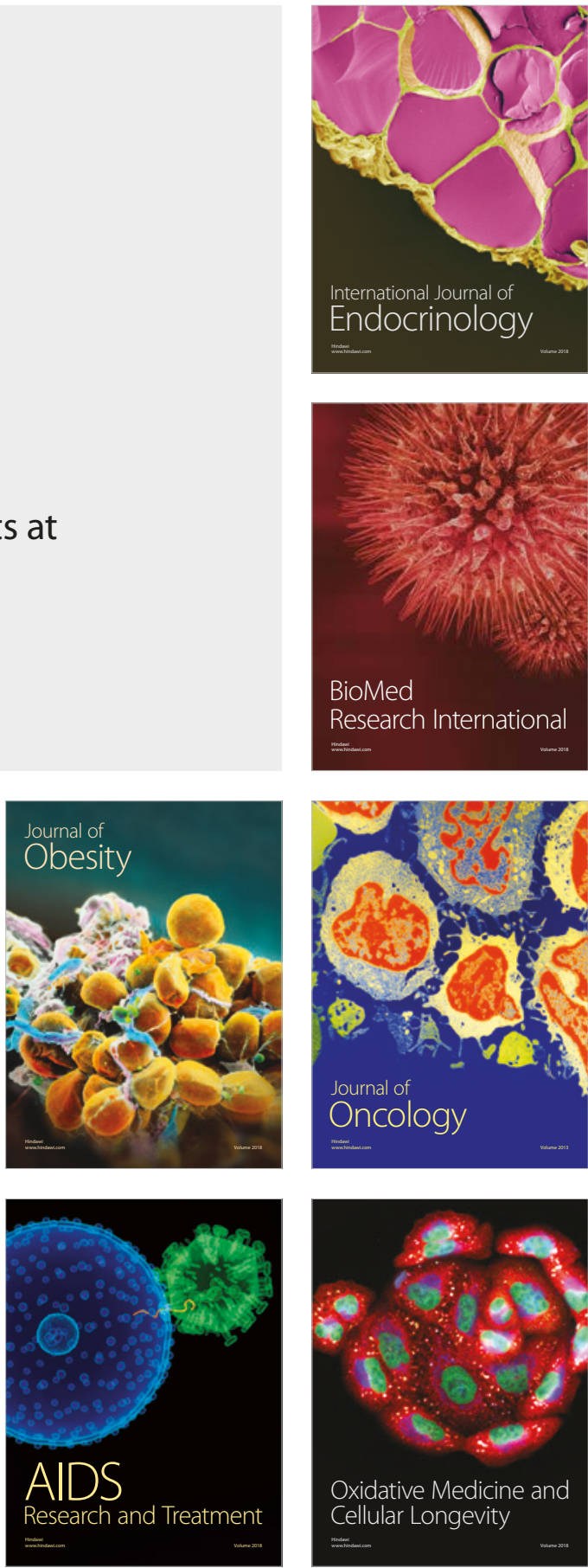